\title{
EaD NA FORMAÇÃO E CAPACITAÇÃO DE SERVIDORES PÚBLICOS E DA SEGURANÇA PÚBLICA - REFLEXÕES
}

\author{
Sônia Maria Dall'Igna ${ }^{1}$ \\ Fernando José Spanhol ${ }^{2}$ \\ Marcio Vieira de Souza ${ }^{3}$
}

\section{INTRODUÇÃO}

Moore e Kearsley (2008) conceituam o ensino a distância como o aprendizado planejado que ocorre normalmente em um lugar diferente do local de ensino, exigindo técnicas especiais de criação do curso e de instrução, comunicação por meio de várias tecnologias e disposições organizacionais e administrativas especiais.

A Educação a distância (EaD), no mundo inteiro, é uma modalidade voltada à aprendizagem de adultos, vinculada a vários princípios educacionais, entre os quais os de aprendizagem aberta e os de aprendizagem ao longo de toda a vida ou educação permanente. No Brasil, a EaD está sendo adotada na educação, nos programas de qualificação e formação profissional e na educação corporativa.

Escolas de governo na Europa, no Canadá e no Brasil estão adotando a educação a distância em todas as suas formas na oferta de cursos para servidores públicos e comunidade.

Há escolas de governo europeias que possuem programas bastante desenvolvidos de EaD, haja vista o Instituto de Gestão Pública e Desenvolvimento Econômico (IGPDE) da França, o Instituto Nacional de Administração Pública (INAP) da Espanha, e a Escola Canadense do Serviço Público (CSPS) do Canadá.

Considerando essa definição, conclui-se que é possível a EaD ser utilizada com professor e aluno desenvolvendo atividades pedagógicas no mesmo local, mas em tempos diferentes, ou ao mesmo tempo, mas em locais diferentes. É possível, ainda, a utilização da EaD com professor e aluno em locais e tempos diferentes. As TICs (Tecnologias da Informação e Comunicação) estão transformando a noção de tempo e de espaço, sendo que, atualmente, tudo acontece no tempo presente, inclusive as novas formas de ensino e aprendizagem, que podem acontecer em tempo real, mediadas pela tecnologia (CASTRO, 2008).

1Universidade Federal de Santa Catarina, e-mail: sonia-dalligna@ssp.rs.gov.br

2Universidade Federal de Santa Catarina, e-mail: fernando.spanhol@ufsc.br

3Universidade Federal de Santa Catarina, e-mail: marcio.vieira@ufsc.br 
O desenvolvimento das novas tecnologias e sua apropriação pela sociedade, em especial a dinâmica do fluxo de informações em tempo real ou não, proporcionada por aparelhos receptivos, como TV, DVD, videogame, etc., e pelo uso de aparelhos interativos, como celulares, tablets e computadores, com utilização da internet, combinam várias formas de comunicação, como textos, sons e imagens, tornando a transmissão da informação, o conhecimento e o entretenimento mais atrativos e interativos.

A revolução tecnológica está popularizando-se de forma intensa, quer seja pela maior oferta de produtos, com preços cada vez mais competitivos para permitir maior apropriação por parte da população; quer seja pelo incentivo estatal na disponibilização de estrutura de acesso à internet, como quiosques, visando reduzir a exclusão social digital (GUERREIRO, 2006); quer seja pela utilização das novas tecnologias no ambiente escolar e, em alguns casos, pré-escolar.

Belloni (2009) menciona que a EaD é um sistema interpretado como solução frágil e apontado como ensino de baixa e duvidosa qualidade. Entretanto, ela ressurgiu no século XXI, por adequar-se às exigências e características da sociedade atual, como solução, com amplas possibilidades de elevar a qualidade e ampliação do ensino.

A incorporação nos métodos de aprendizagem das organizações de ensino com o intenso desenvolvimento das TICs foi incentivada pelo governo, que reconheceu a EaD como modalidade de ensino, conforme dispõe o Art. 80 da Lei no 9.394/96 (Lei de Diretrizes e Bases da Educação Nacional - LDBEN), conforme redação dada pelo Art. $1^{\circ}$ do Decreto $\mathrm{n}^{\circ} 5.622 / 2005$, conforme segue:

A Educação a Distância caracteriza-se como uma modalidade educacional na qual a mediação didático-pedagógica nos processos de ensinoaprendizagem ocorre com a utilização de meios e tecnologias de informação e comunicação com estudantes e professores desenvolvendo atividades educativas em lugares ou tempos diversos (BRASIL, 2005, p.1).

Dependendo da forma como for utilizada, a educação a distância (EaD) tem a possibilidade de apresentar vantagens combinadas, tais como: flexibilidade de horário para que o aluno faça o curso de acordo com a sua agenda; controle do próprio ritmo de aprendizagem; adaptação à realidade; instantaneidade da informação; interatividade entre os participantes; material didático e planejamento de ensino estruturado e adaptado às especificidades do curso; oferta em diferentes localidades; redefinição dos processos de aprendizagem organizacional; e o que 
mais conta, custo reduzido (SANTOS; MEDINA, 2005; RICARDO, 2005; NASCIMENTO, 2006).

Como afirma Moreno (2002, p.105), "antes do mundo digital, a comunicação tradicional exigia a sincronicidade e presença física. Num mundo assíncrono, como o chamado ciberespaço, tudo pode ser virtual". A educação a distância possibilita "combinar soluções pedagógicas adaptadas a cada tipo de aluno, às peculiaridades da organização, às necessidades de cada momento" (MORAN, 2005, p. 7).

\section{EDUCAÇÃO A DISTÂNCIA - UM BREVE HISTÓRICO}

Segundo Chermann e Bonini (2000), a educação a distância passou por diversas fases e está na quinta geração. A primeira usou o modelo de correspondência, surgiu da evolução dos serviços postais e da massificação da mídia impressa. A segunda geração utilizou a mídia impressa, fita de áudio, vídeo, vídeos interativos (disco e fita) e a difusão de rádio e televisão chamada Ensino Mediatizado, com raras interações do professor, as quais ocorriam com a devolutiva de documentos escritos ou a utilização do telefone. A terceira geração passou a utilizar a multimídia interativa, com o uso do computador e o modelo de teleaprendizagem, como audioconferência, videoconferência, transmissão de TVrádio e audioteleconferência, com sistemas bidirecionais, síncronos e assíncronos, com interatividade entre professores e alunos por rede de computadores. A quarta geração utilizou o modelo de aprendizagem flexível, com o aparecimento das salas virtuais e até mesmo instituições que para os alunos são virtuais, com professores e colegas de turma virtuais, com o uso da multimídia interativa on-line e acesso via internet e recursos da comunicação mediatizada por computador. A quinta geração utiliza o modelo de aprendizagem flexível inteligente, com uso das mídias das gerações anteriores, sistemas de respostas automáticas e acesso via portal da instituição, com todo o processo sistematizado e informatizado (DIAS; LEITE, 2010; GOMES, 2013).

As instituições de ensino superior brasileiras, na década de 1990, começam a se interessar por esse mercado, principalmente devido à maior facilidade de comunicação via internet. Em 1992, a Lei n`403/92 criou a Universidade Aberta de Brasília cujos campos de trabalho envolvem a ampliação do 
conhecimento cultural com a organização de cursos específicos. Foram criados cursos para atender à reciclagem profissional e ao ensino superior de graduação e pós-graduação. A Lei de Diretrizes e Bases da Educação Nacional n 9.394, de 20 de dezembro de 1996, regulamentada pelo decreto $n^{\circ} 5.622$, de 20 de dezembro de 2005, trouxe as bases legais para a modalidade da educação a distância. No caput de seu artigo 80 consta que a EaD será incentivada pelo Poder Público.

Dados do Anuário Brasileiro Estatístico de Educação Aberta e a Distância deixam claro que essa forma de educação veio para ficar e que a tendência é que tenha um aumento nos próximos anos.

A educação corporativa no Brasil e em outros países está crescendo rapidamente, calcada na oferta de cursos por meio de ambientes virtuais de aprendizagem que possibilitam ao aluno e ao professor a interação assíncrona e a veiculação de objetos de aprendizagem pela Internet.

Em organizações públicas e privadas, a EaD amplia e democratiza o acesso de pessoas ao estudo e cria condições propícias à aprendizagem contínua. O uso de plataforma eletrônica de gerenciamento da aprendizagem tem possibilitado a armazenagem e a organização de verdadeiras universidades virtuais com serviços de orientação profissional, guias de estudo ou trilhas de aprendizagem, cursos mediados pela intra ou internet, bibliotecas virtuais, textos e materiais de apoio ao estudo em diferentes áreas.

A pergunta que se faz é se a EaD possui características que incorporam a sistemática de ensino às formas de adquirir conhecimento. Para isso tem que atender aos chamados pilares da educação:

O aprender a conhecer: decorrente da necessidade de o indivíduo, em um cenário em que o conhecimento torna-se cada vez mais instável, estar continuamente inserido em um processo de compreensão, descoberta, construção e desconstrução do conhecimento. Mais do que aprender conteúdos, é necessário conhecer linguagens e metodologias a partir das quais os conhecimentos são gerados e transferidos;

$>$ O aprender a fazer: relaciona-se às habilidades e atitudes supostamente capazes de tornar o indivíduo constantemente apto a enfrentar novas e desafiadoras situações, inclusive de trabalho. À medida que aumenta o descompasso entre as oportunidades de educação 
superior e as exigências impostas pelo mundo do trabalho, cada vez mais se torna insuficiente a preparação profissional para uma atividade específica e uma realidade estática. É preciso que essa preparação seja contínua e abrangente;

$>\mathrm{O}$ aprender a viver junto: refere-se às habilidades e atitudes que permitem ao indivíduo conviver bem com outras pessoas em um cenário em que os trabalhos, cada vez mais complexos, exigem a atuação profissional em equipes interdisciplinares para a solução de problemas;

O aprender a ser: refere-se ao desenvolvimento integral da pessoa. É preciso que o ser humano se desenvolva plenamente em todas as potencialidades (DELORS, 2005).

Esses pilares oferecem os rumos para um processo educacional em que o "aprender a aprender" torna-se essencial, na medida em que o conhecimento baseado na compreensão da realidade assume posição de destaque no atual mundo do trabalho.

É evidente que, diante dos desafios do mundo atual, a EaD se apresenta como um colaborador de magnífica valia nas esferas do serviço público.

O profissional do presente e do futuro terá que se interessar pelo aperfeiçoamento de sua aprendizagem para atingir objetivos de qualidade e de gestão no oferecimento o do serviço público ao longo de toda a sua vida profissional.

\section{EDUCAÇÃO A DISTÂNCIA E SERVIDORES PÚBLICOS}

Atualmente, o contingente de servidores públicos ultrapassa a casa dos 11,1 milhões de pessoas no Brasil (fig. 1), considerando todos os níveis de governo, e seu desempenho profissional é requisito essencial à gestão pública, que visa aos resultados, ainda mais nos dias atuais em que a aprendizagem constante ao longo da vida é exigida em todas as organizações.

A sociedade atual privilegia 0 conhecimento, sendo que 0 aperfeiçoamento constante de habilidades é quase um pré-requisito. Por isso, muitas empresas aumentaram seus investimentos em programas de treinamento, desejosas por uma gestão moderna, com o objetivo voltado para os resultados. Os 
governos necessitam de servidores capacitados a atender demandas crescentes da população cada vez mais exigente quanto à eficiência dos serviços públicos, por isso seguem esse mesmo caminho (OSBORNE; GAEBLER, 1994).

O papel do servidor, a sua motivação e capacitação passaram a ser objeto de estudo no modelo gerencial de administração pública, na busca de reformas administrativas para aumentar a eficiência quanto à prestação dos serviços públicos ofertados (BRESSER PEREIRA, 1996). O modelo gerencial preconiza mais autonomia e responsabilidade ao servidor para o cumprimento de metas e resultados, com foco no desenvolvimento de competências por meio da capacitação profissional.

A identificação das características presentes no perfil do agente público nos modelos patrimonialista, burocrático e gerencial, considerando o contexto da sociedade brasileira, aliado à necessidade atual de capacitação contínua dos agentes públicos, com a utilização da metodologia da educação a distância, torna esta pesquisa uma contribuição relevante para o meio acadêmico.

Trata-se de uma oportunidade de se contribuir para a compreensão desse fenômeno que aproxima a gestão urbana da gestão empresarial (responsável por moldar uma convergência de conceitos, interpretações, ações e práticas distintas), as quais têm, em sua origem, objetivos completamente opostos.

Os funcionários públicos são os que conduzem a estrutura do Estado, que precisa ser comandado para atingir seus objetivos. De acordo com Bergue (2010, p.31), são rotineiras expressões como: "as pessoas são o principal ativo da organização" ou "sem os servidores não há prestação de serviços públicos de qualidade". A busca da excelência remete à importância da capacitação profissional, que é o "processo permanente e deliberado de aprendizagem, com o propósito de contribuir para o desenvolvimento de competências institucionais por meio do desenvolvimento de competências individuais" (BRASIL, 2006) e tem como principal missão a eficiência e eficácia do serviço público realizado, cuja principal finalidade é o bem comum.

O agente público, com o avanço tecnológico, necessita ter flexibilidade para receber novos conhecimentos, adquirir novas habilidades e ter atitudes que demonstrem o seu profissionalismo.

As organizações, incluído as públicas, têm despertado para a importância das pessoas como principal recurso, pois são essas pessoas que 
compõem as organizações e decidem o rumo de suas ações. São elas que gerenciam os recursos materiais, tecnológicos, a estrutura, as informações e conhecimento. Para Drucker (1997, p.51), "o principal recurso de capital, o investimento fundamental e o centro de custos de uma economia desenvolvida é o trabalhador intelectual, aquele que põe a funcionar tudo que seu intelecto absorveu [...]".

Após sondar o universo de órgãos públicos que se apropriaram das TIC's para proporcionar o ensino a distância, destacar-se-ão duas grandes instituições voltadas ao ensino e aperfeiçoamento de servidores públicos, bem como serão explicitadas as suas formas de atuação. Inicialmente, a ENAP - Escola Nacional de Administraçao Pública, voltada ao aperfeioamento de servidores públicos em geral; depois, a SENASP/EaD, Rede Nacional de Ensino a Distância da Secretaria Nacional de Segurança Pública, que tem como finalidade aperfeiçoar agentes de segurança pública em especial.

\section{ENAP - ESCOLA NACIONAL DE ADMINISTRAÇÃO PÚBLICA}

A Fundação Escola Nacional da Administração Pública (Enap) é uma escola de governo, do Poder Executivo Federal, que oferece formação e aperfeiçoamento em Administração Pública para servidores públicos federais e está inserida no processo de ampliação do acesso à educação continuada e à aprendizagem ao longo da educação a distância. É vinculada ao Ministério do Planejamento, Orçamento e Gestão e foi criada em 1986. É regida pelas disposições da Lei oㅜ 6.871, de 3 de dezembro de 1980, com as alterações da Lei ํo 8.140, de 28 de dezembro de 1990; pelo estatuto aprovado na forma do Decreto ํo 6.563, de 11 de setembro de 2008, alterado pelo Decreto ํ 8.091, de 03 de setembro de 2013; e por seu Regimento Interno e legislação complementar.

Oferece aos servidores públicos brasileiros, atualmente, mais de 20 cursos a distância através de sua Escola Virtual, com e sem tutoria.

A ENAP adota vários recursos de interação, com estudo e exercícios em salas de aula virtuais, utilizando como estratégias de ensino-aprendizagem o uso de correio eletrônico e de salas de bate-papo, comunidades de aprendizagem e exercícios. Como forma de ultrapassar fronteiras, a ENAP firmou acordos e parcerias com escolas de governo de outros países (Espanha, França e Canadá) para promover o intercâmbio de experiências em $\mathrm{EaD}$, estimulando a formação 
desse tipo de comunidade por meio da inclusão dessa ferramenta como estratégia para unir pessoas em torno de temáticas de interesse recíproco e para apoiar a realização de cursos a distância mediados por Internet.

Essa instituição é composta pelos seguintes setores: Gabinete da Presidência, Diretoria de Formação Profissional (DFP), Diretoria de Desenvolvimento Gerencial (DDG), Diretoria de Comunicação e Pesquisa (DCP), Diretoria de Gestão Interna (DGI), Assessoria de Cooperação Internacional (ACl), Procuradoria Federal e Auditoria.

A ENAP tem a responsabilidade de ofertar programas de capacitação para os servidores ocupantes dos cargos de Direção e Assessoramento Superiores. Capacitar e formar servidores para atuarem de modo congruente com os desafios do ciclo de gestão; preparar servidores para assumirem crescentes responsabilidades expressas nos cargos comissionados; atender às demandas de novos segmentos que precisam ampliar suas competências de gestão; e desenvolver ações formativas para altos dirigentes da administração pública, searas que constituem o campo principal de atuação da ENAP no que tange à implementação de programas de formação e capacitação.

Por fim, é importante ressaltar como um público-alvo potencial da ENAP os formadores das escolas de governo. Do ponto de vista estritamente institucional, essa escola não possui tal atribuição, no entanto, o seu acúmulo de experiências no campo da formação de servidores públicos, associado à tradição de prospecção de conteúdos e tecnologias educacionais nas escolas nacionais e estrangeiras e à sua forte inserção na administração pública federal tornaram a ENAP uma referência para outras escolas de governo, tanto federais setoriais como de outras esferas e poderes. Assim, nos últimos anos, têm sido implementadas várias iniciativas voltadas à atualização de docentes colaboradores das escolas de governo, além de outras que envolvem os dirigentes e técnicos das escolas nos processos de intercâmbio de conhecimentos e experiências sobre a implementação de programas formativos para servidores.

Para se inscrever, basta ser funcionário público e preencher a ficha de inscrição disponível no seguinte endereço eletrônico: http://www.enap.gov.br

\section{SENASP - SECRETARIA NACIONAL DE SEGURANÇA PÚBLICA (REDE NACIONAL DE ENSINO A DISTÂNCIA/REDE EAD-SENASP)}


Criada em 2005 pela Senasp/MJ, em parceria com a Academia Nacional de Polícia, a Rede Nacional de Ensino a Distância/Rede EaD-Senasp é uma escola virtual destinada aos profissionais de segurança pública de todo o Brasil, a qual tem como objetivo viabilizar o acesso desses profissionais à capacitação continuada, independentemente das limitações geográficas e considerando as peculiaridades institucionais existentes.

Com a implementação da Rede $\mathrm{EaD}$, a Senasp/MJ passou a exercer 0 papel de efetivo órgão condutor dos processos de educação em segurança pública, promovendo a articulação entre as Academias, Escolas e Centros de Formação e Aperfeiçoamento dos Operadores de Segurança Pública de todo o Brasil, a partir de uma postura de respeito às autonomias institucionais, bem como aos princípios federativos.

A Rede EaD-Senasp possibilita aos Policiais Federais, Rodoviários Federais, Civis, Militares, Bombeiros Militares, Profissionais de Perícia Forense, Guardas Municipais e Agentes Penitenciários Estaduais o acesso gratuito à educação continuada, integrada e qualificada.

A Rede está implementada nas 27 Unidades da Federação, por meio de 270 telecentros já instalados nas capitais e principais municípios do interior. Os cursos são disponibilizados por meio de ciclos. A cada ano, realizam-se três ciclos de aulas, dos quais participam, aproximadamente, 100 mil alunos por ciclo. São mobilizados dois mil tutores ativos para as mais de duas mil turmas, que contam com até 50 alunos por sala virtual.

A Rede é um salto qualitativo em termos de investimento no capital humano, na valorização do profissional de segurança pública, na busca da excelência nas ações de capacitação continuada e, consequentemente, na melhoria das ações voltadas à segurança pública.

Com o fortalecimento da Rede EaD-Senasp, o Governo Federal estabelece uma política na qual os processos de aprendizagem são contínuos e sistêmicos, garantindo, assim, a coerência com as demais políticas de melhoria da qualidade da educação em segurança pública. Seus objetivos principais são:

Dotar as Unidades Federativas de um ambiente de ensino, mediado pela tecnologia de TV digital e Internet para comunicação e informação; 
> Disseminar/compartilhar conhecimentos e informações para todos os profissionais da área de segurança pública, estimulando doutrinas e práticas unificadas independentemente da distância;

Favorecer o diálogo social entre as diversas instituições que compõem o sistema de Segurança Pública;

> Ampliar a rede de pessoas que pensam e fazem a segurança pública;

> Contribuir com a integração dos profissionais da área de Segurança Pública;

> Promover a consolidação das Políticas Públicas na Área de Segurança Pública;

> Implementar ações de capacitação permanente de forma sistematizada;

Registrar o capital intelectual das instituições/profissionais da área de Segurança Pública.

A utilização dos métodos tradicionais de acesso à capacitação, exclusivamente presenciais, dadas as restrições de custo, tempo, distância e disponibilidade, já não atendiam aos desafios educacionais e de treinamento da área de segurança pública brasileira, tendo em vista o número expressivo desses profissionais, as dimensões geográficas brasileiras e realidades distintas evidenciadas no país.

Os elevados custos, diretos e indiretos, associados aos deslocamentos e hospedagens e às dificuldades relacionadas aos afastamentos dos locais de trabalho para participação em cursos presenciais restringem o acesso à educação, na área da segurança pública, a um grupo muito reduzido de pessoas.

No sentido oposto, a utilização de novas tecnologias aplicadas à educação, notadamente a televisão por satélite e a internet, proporciona a disseminação do conhecimento para contingentes cada vez maiores. Além disso, há uma redução de custos na medida em que cresce o número de participantes no aprendizado, justificando plenamente o investimento inicial com equipamentos, redes de comunicação e desenvolvimento de conteúdos.

A estratégia adotada pela Rede EaD-Senasp foi integrar, por meio de uma rede nacional de telecomunicações, as ações do sistema educacional 
presencial e a distância. A execução é feita em conjunto com as Academias de Polícia, respeitadas as peculiaridades e a autonomia das instituições de segurança pública nos vários níveis, já que o público-alvo a ser atingido apresenta grande diversidade nos seus focos de atuação e considerável abrangência geopolítica.

A atenção com o conteúdo pedagógico está presente em toda a arquitetura da Rede EaD-Senasp. Foram formadas equipes especializadas de educadores, conteudistas e pedagogos, conhecedores dos temas e das questões afetas à segurança pública para elaborar e acompanhar o desenvolvimento e a implantação de todas as etapas do processo educacional.

A solução tecnológica elaborada consiste na montagem da infraestrutura de Tecnologia de Informação baseada em rede, com telecentros instalados nas instituições de segurança pública de cada Unidade da Federação. Os telecentros integram os recursos do canal corporativo de televisão e da Internet, reunindo avançadas tecnologias aplicadas à educação e podendo, na sua expansão, atender ao acesso à educação continuada do contingente humano formado pelas mais de 600 mil pessoas dedicadas à segurança pública no Brasil.

Os cursos disponibilizados por meio da Internet capilarizam o acesso, permitindo que o profissional de segurança pública possa, em qualquer lugar, e no tempo que Ihe for disponível, conectar-se e estudar os conteúdos sem qualquer restrição, atendendo às pecualiaridades de sua profissão e cargo.

Atualmente, são disponibilizados na Rede EaD-Senasp 63 cursos, os quais abordam os mais diversos temas voltados à capacitação continuada dos profissionais de segurança pública.

A partir de 2012, vêm sendo instituídas Câmaras Técnicas, objetivando garantir a qualidade dos cursos da Rede EaD-Senasp, por meio da análise da coerência e densidade dos conteúdos, como também da propositura de atualizações pertinentes. Dessa forma, todos os novos cursos a serem disponibilizados pela Rede passarão pela análise colegiada da Câmara Técnica e os cursos já disponibilizados serão gradativamente analisados e submetidos a adequações técnicas e atualizações, quando necessárias.

As inscrições sempre são realizadas três vezes por ano: janeiro, maio e agosto. Para se inscrever, basta ser funcionário público da segurança e preencher a ficha de inscrição disponível, em épocas pré-determinadas, no seguinte endereço eletrônico: http://ead.senasp.gov.br/ficha_inscricao/aviso_sem_cliente.asp. 
Para informações adicionais sobre os cursos, datas e conteúdos, basta acessar o site do Ministério da Justiça (http://portal.mj.gov.br).

\section{REFLEXÕES}

A capacitação do servidor público deve permitir o aprimoramento de suas competências técnicas e comportamentais, e mais que isso, considerar a complexidade das funções, atividades, atribuições e responsabilidades, bem como o resultado ou o retorno à gestão (LEME, 2006). Para tanto, o servidor público, nomeado para o exercício de suas funções em qualquer setor, necessita de auxílio para conhecer as atividades relacionadas à sua função. As informações relativas às novas atribuições e à adaptação do servidor geralmente contam com o apoio dos servidores públicos que já estão desempenhando atividades no local. Ainda que se esforcem, quer seja pela falta de tempo, quer seja pelo excesso de atividades, falta de conhecimento especializado ou mesmo aptidão para transmitir o conhecimento tácito, raros são os servidores que prestam serviço de mentoria (VERGARA, 2012, p.109).

Considerando o grande número de servidores públicos, sendo a exigência legal de eficiência extensiva a todos os agentes públicos, passa a ser um desafio capacitá-los, tendo vista que os modelos tradicionais de ensino (ensino presencial), além de limitarem o acesso por não possuírem vaga disponível para todos, limitam o acesso em virtude da necessidade de mobilização até o local de realização dos cursos e por seus custos crescentes (MEDEIROS, 2010).

Nesse contexto, é necessária a discussão de estratégias de desenvolvimento profissional que possam dar respostas rápidas e de alta qualidade a grandes contingentes de servidores em organizações públicas que precisam desenvolver características próprias da gestão pública gerencial, para que tenham igualdade de oportunidades e possam maximizar a utilização dos recursos públicos (NASCIMENTO, 2006).

Por outro lado, na segurança pública, é imperativa a expansão do ensino que além de preparar o agente para a sua função peculiar, promova o aperfeiçoamento permanente e continuado, para que os contigentes de segurança estejam em dia com o seu tempo, acompanhando as aceleradas mudanças sociais, 
com novos temas a serem estudados, tais como as técnicas cada vez mais sosfisticadas, colocadas em prática, por exemplo, do crime organizado.

A mudança de paradigma nessa nova era do conhecimento é complexa e vai além das questões tecnológicas, mas é necessária. Elas incluem transformações comportamentais, de cultura e de atitude entre os diferentes atores sociais, com o uso e apropriação das TICs, as quais possibilitam novas formas de estar, perceber e sentir o mundo, com novas formas de comunicação (BARBOSA FILHO; CASTRO, 2008).

\section{CONSIDERAÇÕES FINAIS}

A Educação a Distância é a modalidade de ensino mais democrática das formas de se adquirir conhecimento, eis que utiliza de tecnologias de informação e comunicação para transpor obstáculos e revolucionar as formas convencionais de ensino. Essa sistemática de repassar conhecimento vem ampliando suas fronteiras e democratizando cada vez mais o ensino por meio de ferramentas virtuais para transmitir os mais variados conhecimentos, essencialmente por ser um instrumento capaz de atender um grande número de alunos simultaneamente, chegando aos servidores que estão distantes dos locais onde são ministrados os ensinamentos e/ou que não podem estudar em horários pré-estabelecidos.

Por outro lado, os servidores públicos somam, como foi visto, mais de 11,1 milhões de pessoas na atualidade. Na segurança pública, estão ativos 675 mil agentes, entre policiais civis, militares e guardas municipais. Seria impossível mantêlos atualizados em seus deveres específicos por meio de cursos e capacitações presenciais, utilizando-se métodos de ensino tradicionais.

Assim, a EaD chegou para contribuir nesta hercúlea tarefa de repassar conhecimento a esse contingente essencial para a boa prestação de serviços públicos, tanto no caso dos servidores em geral, como no caso especialíssimo dos servidores da segurança pública.

Já está provado que o sistema funciona, as plataformas utilizadas se aperfeiçoam e a qualidade dos cursos oferecidos é ascendente. São grandes, portanto, as possibilidades da EaD nesse meio no que concerne ao treinamento, capacitação e aperfeiçoamento, com custo zero aos alunos, facilitando-se a vida daqueles que desejam obter mais conhecimento, mas cujo tempo é exíguo. Como 
os cursos a distância independem de espaço especial e demarcado para acontecerem, sem falar na flexibilidade de horários, o aprendizado torna-se adequado aos tempos e espaços que o servidor dispõe para aprender.

No início deste século, o sistema de aprendizagem a distância já estava consolidado, entretanto, sofria pela desconfiança que gerava em virtude da forma livre de sua oferta, novidade para os que estavam habituados a participar de cursos presenciais. Os pessimistas asseveravam que o aluno necessitaria, para absorver conteúdos, da presença do professor-tutor, cobrando atenção e desempenho. No entanto, a gradativa disseminação dos cursos a distância demonstrou que o aluno pode se dedicar mesmo fora das salas de aula, criando seus próprios métodos de dedicação e cumprimento de tarefas avaliados por um tutor a distância.

Superadas as dificuldades iniciais, como foi visto, quando de sua implantação, em 2005, tanto a ENAP quanto a SENASP evoluíram suas plataformas, disponibilizaram um número cada vez maior de cursos e treinaram tutores para atender à demanda de alunos que cresceu geometricamente.

Hoje, é uma realidade sólida que veio para ficar. Os cursos são oferecidos periodicamente, as turmas são distribuídas às tutorias e os capacitados absorvem os conhecimentos necessários à prática de seus afazeres, aplicando na prática os conteúdos disponibilizados, numa grande rede de educação que alimenta permanentemente seus agentes públicos com os saberes que lhes facilitam a execução de seus misteres e tarefas profissionais.

\section{REFERÊNCIAS}

ABBAD, G. da S. Educação a distância: o estado da arte e o futuro necessário. In: Revista do Serviço Público, Brasília, v. 58, n. 3, jul./set. 2007.

ABBAD, G.; CARVALHO, R. S.; ZERBINI, T. Evasão em curso via internet: explorando variáveis explicativas. Revista deadministração de empresas - RAE eletrônica, São Paulo, v. 5, n. 2, jul./dez. 2006. (Art. 17).

BARBOSA FILHO, A.; CASTRO, C. Comunicação Digital: educação, tecnologia e novos comportamentos. São Paulo: Paulinas, 2008.

BELLONI, M. L. Educação a distância. Campinas: Autores Associados, 2009.

BERGUE, S. T. Especialização em gestão de pessoas no serviço público: uma perspectiva da vivência docente no contexto do curso. In: PANTOJA, M. J.; CAMÕES, M. R. de S.; BERGUE, S. T. (Orgs.). Gestão de pessoas: bases teóricas e experiências no setor público. Cap. II, Brasília: ENAP, 2010. 
BRASIL. Decreto ํㅜ 5.622, de 19 de dezembro de 2005. Regulamenta o art. 80 da Lei no 9.394, de 20 de dezembro de1996, que estabelece as diretrizes e bases da educação nacional. Diário Oficial [da] República Federativa do Brasil.Brasília, DF, 20 dez. 2005.

BRASIL. Lei no 8.112, de 11 de dezembro de 1990. Modifica o regime e dispõe sobre princípios e normas da Administração Pública, servidores e agentes políticos, controle de despesas efinanças públicas e custeio de atividades a cargo do Distrito Federal, e dáoutrasprovidências. Diário Oficial [da] República Federativa do Brasil. Brasília, DF, 12 dez. 1990.

BRASIL. Ministério da Justiça. Secretaria Nacional de Segurança Pública. Matriz Curricular Nacional: Para as Ações Formativas dos Profissionais da Área de Segurança Pública. Versão Modificada e Ampliada. Brasília, DF: SENASP, 2008.

BRASIL. Constituição da República dos Estados Unidos do Brasil (1.934). Diário Oficial [da] República Federativa do Brasil. Brasília, DF, 16 jul. 1934.

BRASIL. Decreto no 5707, de 23 de fevereiro de2006. Institui a Política e as Diretrizes para o Desenvolvimento de Pessoal da administração pública federal direta, autárquica e fundacional, e regulamenta dispositivos da Lei ํㅡ 8.112 , de 11 de dezembro de 1990.Diário Oficial [da] República Federativa do Brasil. Brasília, DF, 24fev. 2006.

BRASIL. Constituição (1998). Emenda constitucional no 19, de 04 de junho de1998. Modifica o regime e dispõe sobre princípios e normas da Administração Pública, servidores e agentes políticos, controle de despesas e finanças públicas e custeio de atividades a cargo do Distrito Federal, e dá outras providências. Diário Oficial [da] República Federativa do Brasil. Brasília, DF, 04 jun. 1998.

BRESSER PEREIRA, L. C.; SPINK, P. Reforma do Estado e administração pública gerencial. 7. ed. Rio de Janeiro: FGV, 2008.

CARVALHO, A. I. de et al. Escolas de Governo e gestão por competências: mesa-redonda de pesquisa-ação. Brasília: ENAP, 2009.

CASTRO, C. Tv digital e EaD: uma parceria perfeita para a inclusão digital. In: BARBOSA FILHO, A.; CASTRO, C. (Orgs.). Comunicação Digital: Educação, tecnologia e novos comportamentos. São Paulo: Paulinas, 2008.

CHERMANN, M.; BONINI, L. M. Educação a Distância: Novas tecnologias em ambientes de aprendizagem pela Internet. Liberdade, SP: EPN Editora e Projetos S/S Ltda, 2000.

DELORS, J. A. Educação para o Século XXI: questões e perspectivas. Porto Alegre, RS: Artmed, 2005.

DIAS, M. I. de M. E. A identificação de fatores críticos à implantação de um sistema de avaliação de desempenho em uma Instituição Pública. In: 
PANTOJA, M. J.;CAMÕES, M. R. de S.; BERGUE, S. T. (Orgs.). Gestão de Pessoas: bases teóricas e experiências no setor público. Brasília: ENAP, 2010.

DIAS, R. A.; LEITE, L. S. Educação a distância: da legislação ao pedagógico. 2. ed. Petrópolis: Vozes, 2010.

DIAS, R. A.; LEITE, L. S. Fator Humano e Desempenho: O melhor de Peter F. Drucker sobre a administração. 3. ed. São Paulo: Pioneira, 1997.

FÓRUM BRASILEIRO DE SEGURANÇA PÚBLICA. Anuário Brasileiro de Segurança Pública. 6. ed. São Paulo: Fórum Brasileiro de Segurança Pública, 2013.

GOMES, J. M. Gerações de inovação tecnológica no ensino a distância. 2003. Disponível

em:<http://repositorium.sdum.uminho.pt/bitstream/1822/496/1/MariaJoaoGomes.pdf> Acesso em: 27 jul. 2015.

GUERREIRO, E. P. Cidade digital: infoinclusão social e tecnologia em rede. São Paulo: Senac, 2006.

LEME, R. Avaliação de desempenho com foco em competência: a base para remuneração por competências. Rio de Janeiro: Qualitymark, 2006.

MEDEIROS, V. M. R. de. Programa de Capacitação a distância para servidores públicos: A experiência da Escola de Governo do Rio Grande do Norte. In: CONGRESSO CONSAD DE GESTÃO PÚBLICA, 3., 2010, Brasília. Anais... Brasília,DF: CONSAD, 2010.

MOORE, M.; KEARSLEY, G. Educação a distância: uma visão integrada. Trad. Roberto Galman. São Paulo: Cengage Learning, 2008.

MORAN, J. M. Aperfeiçoando os modelos de EAD existentes na formação de professores. Educação. Porto Alegre, v. 32, n. 3, p. 286-290, set./dez. 2009.

MORENO, J. O futuro das cidades. São Paulo: Editora Senac, 2002.

NASCIMENTO, T. P. C. Educação sem distância: oportunidade para maior profissionalização do servidor público. In: CONGRESO INTERNACIONAL DEL CLAD SOBRE 1를 REFORMA DEL ESTADO Y DE LA ADMINISTRACIÓN PÚBLICA, 11., 2006, Guatemala. Anais... Cidade de Guatemala: 2006.

OLIVEIRA, E. G. Educação a distância na transição paradigmática. 3. ed. Campinas: Papirus, 2008.

OLIVEIRA, R. F. de. Servidores Públicos. 2. ed. São Paulo: Malheiros, 2008. 
OSBORNE, D.; GAEBLER, T. Reinventando o governo: como o espírito empreendedor 1994. está transformando o setor público. Brasília: MH Comunicação,

RAMOS, M. N. Políticas e Diretrizes para a Educação profissional no Brasil. Curitiba: Instituto Federal do Paraná, 2011.

RICARDO, E. J. Educação corporativa e educação a distância: algumas reflexões. In: RICARDO, E. J. (Org.). Educação corporativa e educação a distância. Rio de Janeiro: Qualitymark, 2005.

SANCHEZ, F. (Coord.). Anuário Brasileiro Estatístico de Educação Aberta e a Distância. 4. ed. São Paulo: Instituto Monitor, 2008.

SANCHEZ, F. (Coord.). Anuário Brasileiro Estatístico de Educação Aberta e a Distância. 3. ed. São Paulo: Instituto Monitor. 2007.

SANTOS, L. P.; MEDINA, S. G. P. O processo cognitivo e a aprendizagem Online. In: RICARDO, E. J. (Org.). Educação corporativa e educação a distância. Rio de Janeiro: Qualitymark, 2005.

VERGARA, S. C. Gestão de Pessoas. 11. ed. São Paulo: Atlas, 2012. 